\title{
The ambition of the European Respiratory Journal continues: chapter 5
}

\author{
Marc Humbert ${ }^{1,2,3}$, Anh Tuan Dinh-Xuan ${ }^{4}$, Elin L. Reeves ${ }^{5}$, \\ Matthew G. Broadhead ${ }^{5}$ and Neil J. Bullen ${ }^{5}$
}

Affiliations: 'Univ. Paris-Sud, Université Paris-Saclay, Le Kremlin-Bicêtre, France. ${ }^{2}$ Service de Pneumologie, Hôpital Bicêtre, Assistance Publique Hôpitaux de Paris, Le Kremlin-Bicêtre, France. ${ }^{3}$ INSERM UMR_S 999, Hôpital Marie Lannelongue, Le Plessis Robinson, France. ${ }^{4}$ Service de Physiologie, Paris Descartes University EA 2511. Hôpital Cochin, Assistance Publique Hôpitaux de Paris, Paris, France. ${ }^{5}$ European Respiratory Society Publications Office, Sheffield, UK.

Correspondence: Marc Humbert, Service de Pneumologie, Hôpitaux Universitaires Paris-Sud, Assistance Publique Hôpitaux de Paris, 78 rue du Général Leclerc, 94270 Le Kremlin-Bicêtre, France.

E-mail: marc.humbertabct.aphp.fr

@ERSpublications

A look back at the highlights from the ERJ in 2016, and forward to new developments that will arrive in $2017 \mathrm{http}: / /$ ow.ly/Tezb3074Jfw

Cite this article as: Humbert M, Dinh-Xuan AT, Reeves EL, et al. The ambition of the European Respiratory Journal continues: chapter 5. Eur Respir J 2017; 49: 1602393 [https://doi.org/10.1183/ 13993003.02393-2016].

Happy New Year! As 2017 begins, so too does the final year of the current editorial board's mandate. Welcome to our annual look back at some of the highlights of our past 12 months of publishing, and forward to some of the new developments 2017 will see for the European Respiratory Journal.

As many of you will already know, 2017 marks a transition to continuous publication for the European Respiratory Journal and its sister publication, the European Respiratory Review. The most important motivation behind this decision was improving the service we provide to our authors and readers. In the continuous publication model, the final version of an article is published directly into an "open" issue of the journal; the issue "grows" over time as content is added, until it is considered "closed". In effect, continuous publication will allow us to publish a "version of record" of every article as quickly as possible after it has been through our production processes. This version of record is the final publication of an article, and includes permanent citation details that are immediately indexed and available through platforms such as Web of Knowledge and Medline/PubMed. Previously, articles would be published "in press" initially, and would only have attained a final, permanent citation when they were eventually republished in one of our monthly issues. You may notice that we've made some small changes to our article PDFs, giving more prominence to a "cite this article as" section, to make it clear that page numbers won't be used in article citations any more. Under continuous publication, authors and readers can be assured that whenever we publish an article, its citation details will not change.

Those receiving our printed journal will notice that instead of being distributed at the beginning of the month stated on the front cover, the print edition will be compiled later in the month, at the point when the online issue is "closed" and new content will not be added. (At that time, the following month's online issue is effectively "opened", and available for publication of new content immediately.) Having said this, it should also be recognised that many articles will appear in the printed issue more quickly than they would have under the previous publication model, owing to the reduced time to "final" publication of an article in a journal issue.

Received: Dec 062016 | Accepted: Dec 062016

Conflict of interest: E.L. Reeves, M.G. Broadhead and N.J. Bullen are employees of the European Respiratory Society. Further disclosures can be found alongside this article at erj.ersjournals.com

Copyright @ERS 2017 
Another recent development for the journal has been the introduction of support for authors who wish to share their datasets via the online repository Dryad (datadryad.org). This was our response to the increasing trend toward transparency and data sharing; many authors are now being mandated by their funding bodies to make the raw data that forms the basis for their published results and analyses publicly available for examination by readers and other researchers. Although some of the major general medical journals have started to mandate data sharing for the clinical trials they publish, as a more specialised journal, we have not decided to adopt this approach; however, if any of our authors should wish to, or have been instructed to, publicly archive their datasets, our collaboration with Dryad should facilitate this. A more detailed explainer is available via our manuscript submissions page (erj.ersjournals.com/authors/ms-preparation).

In another response to author and funding body requests, we have also recently introduced new options for those authors and funders who wish to publish their work open access in the European Respiratory Journal. Until recently, open access in the journal meant publishing with a CC BY-NC (creativecommons.org/licenses/by-nc/4. 0) licence only, which restricts re-use to non-commercial purposes. However, over the past couple of years, we have increasingly seen that authors are being mandated by their funding bodies to publish their work open access without this distinction between non-commercial and commercial re-use. As a result, eligible authors can request open access publication with the less restrictive CC BY licence (creativecommons.org/licenses/by/4.0). More details can be found through our "instructions for authors" page (erj.ersjournals.com/authors/instructions). Finally, another change we have made over the past few months is that we have integrated a tool for electronic transfer of copyright via the ScholarOne Manuscripts submission platform (mc.manuscriptcentral.com/erj). This new functionality should help authors to reduce the time spent completing paperwork for this task, while still fulfilling the requirements of the journal for this important element of article publication.

Leaving aside these new developments in how we publish, of course the single, most important aspect for the continuing success of the European Respiratory Journal is what we publish. This past year, we have once again been privileged to receive some of the best research emerging from the field of respiratory medicine. Indeed, 2016 was a recording-breaking year for submissions to the journal, with well in excess of 2500 manuscripts received. As a single journal could not possibly publish such a number of articles, the chief editor, deputy chief editor and all of the associate editors work exceptionally hard all year in order to select the best of these submissions for publication - with tremendous support from our many hundreds of peer reviewers (erj.ersjournals.com/journal/editorial-board). We also work closely with the editors of our companion journals, the European Respiratory Review and ERJ Open Research, to make sure the European Respiratory Society (ERS) journals can offer authors a place for their best articles.

In 2016, we published around 220 original research articles, supplemented by two or three comprehensive review articles in each monthly issue. Of course, we cannot mention here each and every one of the papers that passed our rigorous reviewing process, even if we do feel that all have made a great contribution to the journal. However, some particular highlights from the past year include an analysis of three multinational phase 3 trials of pirfenidone, demonstrating a positive effect on disease progression in patients with idiopathic pulmonary fibrosis [1]; a study elaborating on how identification of four clinical phenotypes in bronchiectasis could enable future dedicated treatment options to be established [2]; a contribution from the ISOLDE study group with new results indicating that blood eosinophil levels may have use as a marker of a COPD patient's response to inhaled corticosteroids [3]; and the results of a phase 2 trial examining the safety and efficacy of bedaquiline when added to existing treatment regimens for multidrug-resistant tuberculosis [4].

In addition to original research articles such as the few mentioned above, the contributions of task force groups continue to comprise an important portion of our selection of published articles, as the official statements and guidelines generated by these expert groups provide essential reading and a "go-to" reference for practising clinicians and researchers. A joint task force established by the ERS and the European Society for Clinical Microbiology and Infectious Diseases published guidelines for the diagnosis and management of chronic pulmonary aspergillosis [5]; another joint venture of the ERS, this time with the European Cystic Fibrosis Society, produced a task force report on the care of adults with cystic fibrosis [6]. Through the year, official ERS statements have been published on the following: the standardisation of lung sound nomenclature [7], diagnosis and management of obstructive sleep disordered breathing in children [8], tele-monitoring for ventilator-dependent patients [9], and exercise testing for the evaluation of intervention efficacy [10]. Later in the year, another important document was published by EMBARC (the European Multicentre Bronchiectasis Audit and Research Collaboration), a clinical research collaboration supported by both the Inhaled Antibiotics in Bronchiectasis and Cystic Fibrosis consortium, a project of the European Union Innovative Medicines Initiative, and ERS. The article identified new priorities for research in bronchiectasis, aiming to set out a roadmap for improving the understanding of bronchiectasis and the quality of care for patients [11].

The quality of the articles published in the journal over the past years was once again underscored by another healthy increase in Impact Factor. Impact Factors for 2015 are calculated from the number of 
FIGURE 1 European Respiratory Journal Impact Factor 2004-2015.

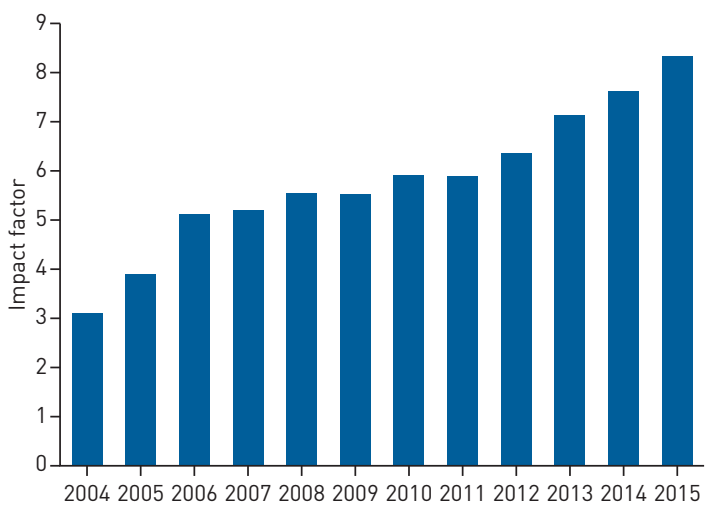

citations made in 2015 to articles published in 2013 and 2014, and were released in June of this year. We were delighted to find that the Impact Factor of the European Respiratory Journal continues to rise, from 7.636 in 2014 to 8.332 this year (figure 1). This was also borne out in the levels of readership achieved by the journal. At the time of writing, the number of visits to the website (erj.ersjournals.com) in 2016 is already more than a quarter higher than in 2015, and the number of article downloads has increased by $55 \%$.

We briefly mentioned our peer reviewers earlier on, but as this conscientious army of experts provides such a crucial foundation to our journals (and, indeed, to all others) they deserve a further comment here. In 2016, we repeated our initiative that commenced the previous year, and asked our board of associate editors to nominate a select few peer reviewers for special recognition of their outstanding contribution to the journal. Congratulations to Christophe Guignabert (Inserm and Université Paris-Sud, France), Luis Puente-Maestu (Hospital Universitario Gregorio Marañón, Madrid, Spain), Nicolas Roche (Université Paris Descartes, France) and Sanja Stanojevic (Hospital for Sick Children, Toronto, Canada), who were awarded for their achievements at the International Congress in London. As always, we will publish the full list of 2016 peer reviewers online early in 2017 - many thanks to all of them. In addition to the peer reviewer awards, we have also over the past year introduced a new associate editor mentoring scheme. The brainchild of associate editor Ramon Farré, this initiative aims to foster the next generation of journal editors; as an internationally recognised journal, we strongly believe in developing these relationships and skills for the future of our community. Briefly, a number of European Respiratory Journal associate editors have each agreed to act as mentors, so that "junior" associate editors can gain experience in coordinating the external peer review process and be party to the decision-making required when selecting manuscripts for publication. We will aim to produce a more detailed report on this venture later in the year.

We hope that you appreciate and enjoy the changes we have brought to the European Respiratory Journal for 2017, whether you are a reader, an author, or both. Thank you to all of you for each playing your part in the achievements we have been able to report to you in this editorial, which will be the last "new year" bulletin from the present editorial team. All the best to you for 2017!

\section{References}

1 Noble PW, Albera C, Bradford WZ, et al. Pirfenidone for idiopathic pulmonary fibrosis: analysis of pooled data from three multinational phase 3 trials. Eur Respir J 2016; 47: 243-253.

2 Aliberti S, Lonni S, Dore S, et al. Clinical phenotypes in adult patients with bronchiectasis. Eur Respir J 2016; 47: 1113-1122.

3 Barnes NC, Sharma R, Lettis S, et al. Blood eosinophils as a marker of response to inhaled corticosteroids in COPD. Eur Respir J 2016; 47: 1374-1382.

4 Pym AS, Diacon AH, Tang S-J, et al. Bedaquiline in the treatment of multidrug- and extensively drug-resistant tuberculosis. Eur Respir J 2016; 47: 564-574.

5 Denning DW, Cadranel J, Beigelman-Aubry C, et al. Chronic pulmonary aspergillosis: rationale and clinica guidelines for diagnosis and management. Eur Respir J 2016; 47: 45-68.

6 Elborn JS, Bell SC, Madge SL, et al. Report of the European Respiratory Society/European Cystic Fibrosis Society task force on the care of adults with cystic fibrosis. Eur Respir J 2016; 47: 420-428.

7 Pasterkamp H, Brand PLP, Everard M, et al. Towards the standardisation of lung sound nomenclature. Eur Respir J 2016; 47: 724-732.

8 Kaditis AG, Alonso Alvarez ML, Boudewyns A, et al. Obstructive sleep disordered breathing in 2- to 18-year-old children: diagnosis and management. Eur Respir J 2016; 47: 69-94.

9 Ambrosino N, Vitacca M, Dreher M, et al. Tele-monitoring of ventilator-dependent patients: a European Respiratory Society Statement. Eur Respir J 2016; 48: 648-663.

10 Puente-Maestu L, Palange P, Casaburi R, et al. Use of exercise testing in the evaluation of interventional efficacy: an official ERS statement. Eur Respir J 2016; 47: 429-460.

11 Aliberti S, Masefield S, Polverino E, et al. Research priorities in bronchiectasis: a consensus statement from the EMBARC Clinical Research Collaboration. Eur Respir J 2016; 48: 632-647. 